\title{
The application example of the comparative analysis in the context of process translation modeling
}

\author{
Vera Shulgan ${ }^{1, *}$ \\ ${ }^{1}$ Peoples Friendship University of Russia (RUDN University), Department of General and Russian \\ Linguistics, 6 Miklukho-Maklaya Str., Moscow, 117198, Russian Federation
}

\begin{abstract}
Currently, a specific mathematical apparatus and methods of mathematical modeling are used to evaluate and verify translations. The theory is just developing and in this article we will show the application of modeling methods on a specific example of studying toponyms. The article is devoted to the consideration of the problem of using toponyms with the connotation inherent in biblicalism in translations of poetic works of the Ukrainian writer I. Franko. A comparative analysis of Russian and English translations clearly shows the discrepancies in the choice of translation strategies that were used in relation to these onyms by Russian and English translators. An attempt to evaluate the quantitative aspect of the comparative analysis of the work of I. Franko in the translation by D. Brodsky, V. Azarov, V. Rich, V. Semenin, P. Dyatlov, P. Kandy and B. Melnik was identified as a research task.
\end{abstract}

\section{Introduction}

Currently, a specific mathematical apparatus and methods of mathematical modeling are used to evaluate and verify translations. The theory is just developing and in this article we will show the application of modeling methods on a specific example of studying toponyms. Toponyms, first of all, have linguoculturological validity, since geographical names introduce a wide historical and cultural background into the text, which is peculiarly actualized in a specific context. This article examines toponyms that have the connotation inherent in biblicalism as a whole, realizing their semantic and pragmatic potential in the Ukrainian original, as well as the translation strategies chosen in relation to these toponyms by Russian and English translators of I. Franko's poetic heritage.

\section{Materials and methods}

Since the creative heritage of the Ukrainian writer I. Franko has more than 50 volumes, seven of which are devoted to poetry, the methodology of our research includes the following methods: descriptive-comparative, ethnolinguistic, statistical methods, as well as historical-cultural, contextual and functional-semantic methods of analysis. The

\footnotetext{
${ }^{*}$ Corresponding author: semenov.venture@mail.ru
} 
methodological principles of our research are formed on the basis of the theory of proper name N.V. Vasilyeva [1], V.M. Kalinkina [2], A.V. Superanskaya [3] and others, as well as the provisions of OI. Fonyakova on the artistic significance of a poetic name as a sign of the onomastic space of a text, manifested in its form (phonetic, morphological) and meaning (nominative, socio-connotative, word-formation, contextual, aesthetic).

\section{Research results}

Exploring the biblical themes in the works of I. Franko, special attention was paid to the poem "Moses", the plot of which is taken by the writer from the Bible. Since the geographical names under study fully realize their semantic and pragmatic potential in original works, there is a need to study their partial changes within the translation text. It should be noted that translators often do not take into account the semantics of proper names, especially when it comes to local expressions using toponyms known only to residents of a small locality.

We decided to classify the most common biblical names found in I. Franco by category items: astyonyms , type of oikonym, proper name of a city (Babylon, Egypt, Jericho, Israel, Mizraim, Jerusalem), hydronyms, type of toponym, proper name of any water object, natural or created by man (Nile, Jordan), buronyms, type of toponym, proper name of any territory, region, district, territory (Palestine, Moab, Canaan, Canaan,), oronyms, type of toponym, proper name of any element of the earth's surface relief which cab have positive $\backslash$ additional (shaft, mountain, hill, rock, Cape) and negative (depression, valley, abyss) (Skymountain).

The statistical method was used as the main method for analyzing the frequency of use of speech units in works in this study.

General scientific method of quantitative research of the text based on identification of probabilistic and statistical data, calculation of the most frequent, leading elements of the text or those components of the text that interest the researcher.

The method of quantitative analysis is significant:

1) when determining the stylistic dominant in the text system, when studying specific language features;

2 ) in the process of generalization and identification of various trends in word usage at the level of usage, individual texts. In connection with the study of the language picture of the world, interest in frequency dictionaries compiled on the basis of a continuous sample has increased.

The point is that quantitative methods in linguistics allow us to perform a multidimensional statistical analysis that reveals the system properties of language and the relationship of language phenomena. They contribute to a more effective analysis of the text, as they give representative results in the study of language. Currently, quantitative indicators are most often used to characterize historical changes in the language and analyze the author's text style. Quantitative methods include simple quantitative analysis, variance analysis, distribution and Central trend analysis, regression and correlation analysis, factor analysis, and others.

In relation to this study, it seems possible to use the first Zipf Law, which states: if you randomly select a random position in the text, the probability of finding a given word in this position is inversely proportional to its frequency. This probability is equal to the ratio of the frequency of a word to the total number of words.

\section{Probability = Frequency / General number of words}




\section{ERSME-2020}

The poem "Moses" is considered the pinnacle of poetry. A deep and philosophical meaning is hidden in this work, because this is not just a poetic compilation of the biblical text, but also a veiled sketch about the future of the Ukrainian people, about the relationship between the leader and the people in the process of persistent search for the "promised land", about the forthcoming forces of the masses, capable of pushing out of their environment in the process of the revolutionary movement of the leaders who will lead to victory. It is in this poem that biblicalisms are often found, which are either transliterated in translations, or even disappear altogether. This can be seen in Table 1 .

Table

1. The

\begin{tabular}{|c|c|c|c|c|c|c|c|c|}
\hline 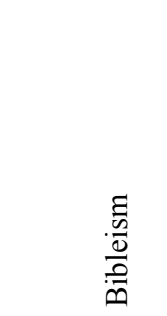 & 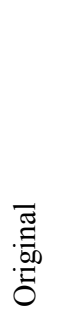 & 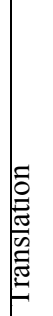 & $\begin{array}{l}\hat{\frac{\pi}{v}} \\
\frac{\vec{v}}{0} \\
\dot{0} \\
e \\
e\end{array}$ & 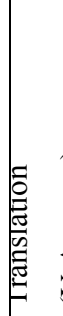 & 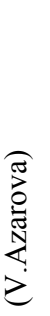 & 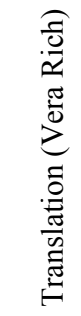 & 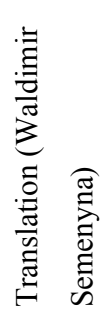 & 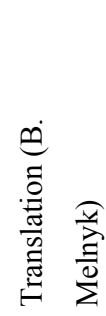 \\
\hline Babylon & 1 & & 1 & & 1 & 1 & 2 & 1 \\
\hline Egypt & 5 & & 6 & & 5 & 10 & 2 & 3 \\
\hline Jericho & 3 & & 3 & & 3 & 3 & 3 & 3 \\
\hline Mitsraim & 2 & & 1 & & 2 & 2 & 2 & 2 \\
\hline $\begin{array}{l}\text { Salim } \\
\text { (Jerusalem) }\end{array}$ & 1 & & 1 & & 1 & 1 & 1 & 1 \\
\hline Jordan & 6 & & 6 & & 7 & 7 & 6 & 5 \\
\hline Nile & 3 & & 3 & & 3 & 3 & 4 & 3 \\
\hline Iзраї (th) 1 & 16 & & 12 & & 10 & 17 & 12 & 7 \\
\hline Kanaan & 4 & & no & & no & 6 & 6 & 6 \\
\hline Canaan & no & & 5 & & 5 & no & no & no \\
\hline Moab & 2 & & 2 & & 3 & 4 & 1 & 2 \\
\hline Palestine & 5 & & 5 & & 5 & 5 & 5 & 4 \\
\hline $\begin{array}{l}\text { Sky } \\
\text { mountain }\end{array}$ & 1 & & 1 & & 1 & 1 & 1 & 1 \\
\hline Total & 49 & & 46 & & 46 & 60 & 44 & 37 \\
\hline
\end{tabular}

number of biblicalisms in the poem "Moses". 
Let's see why this happens with examples. The hydronyms Nile and Jordan are translated with constant frequency, which is explained by the link to the well-known religious primary source, which I. Franko took as a basis. Since the Nile is a river that flows through a depression in a limestone plateau between Aswan and Cairo, and the Jordan is a river in the Middle East that originates at the foot of Mount Hermon, flows through Lake Kinneret and flows into the Dead Sea, we trace the horology [4]. Also here we see the toponym Moab, which, along with the above hydronym Vera Rich has deprived of the shock rhyme position, thereby changing the expressive load of these biblicalisms: Here, too, there are sands red as rust, / Moab's crags sloping barely, / But beyond them the Jordan gleams blue, / Oakgroves, grass springing fairly. [5] We find the same solution in V. Semenina: Though here are sands and Moab`s naked cliffs / Are staring, painted russet-red, / Not far away the Jordan river winds / And flows through groves with pastures clad [6]

No less important in the translation of geographical names is not only the nominative function, but also the determination of the direction of movement to a particular toponym. Even such details are sometimes not taken into account by translators. For example, in B. Turganov's translation: Golden path / Lied from noisy waves / Up to the upper rocks of Athos, - / A wave is rustling below. [7]

In this case, we go from the waves (from below) to the upper rocks, that is, up. And the mountain is here again as a destination, as a desirable peak to which seekers of inner harmony strive. But we see the reverse process in translation into English. P. Kandy describes the path itself and the beauty of the sea, which can be seen from the slopes of Athos. That is, there is no point to which one should strive, there is only a moment of pleasure directly on the spot: The rays obliquely fell and made / A golden pathway o'er the sea / From Athos where its waters beat / Unto the setting sun itself [8]. Another oronim Khoriv from the poem "Moses" is found in the translation of P. Dyatlov [7].

As you can see, there are no additional clarifications on the object of the nomination, the author rhymes the heights of Khoryv with the words marvel and impulse. Thus, the oronym in this poetic fragment has an emotional coloring, emphasizes the attitude of the writer to the geographical object, as to a diva, a miracle, as well as an impulse of sincere feelings about which the writer wants to shout at the top of Horeb. We see a slightly different situation in translation into English:

'Tis Thee alone my soul doth seek; / On Thee alone my heart can count.../ Oh, let me hear Thy voice once more /As Thou didst speak on Horeb's mount! [8]

P. Kandy, specifying that this is still a mountain object, somewhat distorts not only the rhyme position of the toponym (now the oronym is in an unstressed position, and the rhyme is found for the word mount, not Horeb), but also the semantic load imposed on this oronym: on on the top of the mountain, the writer offers to shout about the sincerity of his feelings to the one whom his heart calls; and the translator sees it as a request: «let me hear your voice and shut up / don't talk on the top of the mountain».

Thus, we see that in the process of translating toponymic units, Russian and English translators sometimes find it difficult to search for expressive equivalents, which in turn affects the quality of the translation and the presence of toponymic functions incorporated by the writer in the texts of original works.

It should also be noted that the geographical correspondence of the investigated literary text to reality is preserved both in the original and in its translations into English [9]. Having slightly changed the emphasis, V. Rich [5] and B. Melnik [10] do not distort the connotation. 
Comparison of a personified water body with a mythical creature, which, according to legends, lures tourists in danger with the help of mirages - fata morgana - we see on the example of this excerpt: morgana is evil [4]. At the same time, V. Semenina's personification is fully preserved in her translations.

In addition to preserving the semantic load of toponyms, conveying their original expressiveness, preserving the position of rhyme, which enhances its contextual significance for obtaining the completeness of the described topos, where a poetic event occurs in the original text, translators face another equally important task - to take into account the quantitativeness of the onyms used by the writer. Significant discrepancies indicate a possible interpreter's own interpretation of a work of art (Fig. 1)

\section{Quantitative aspect of the comparative analysis of the bibleisms of poem "Moses"}

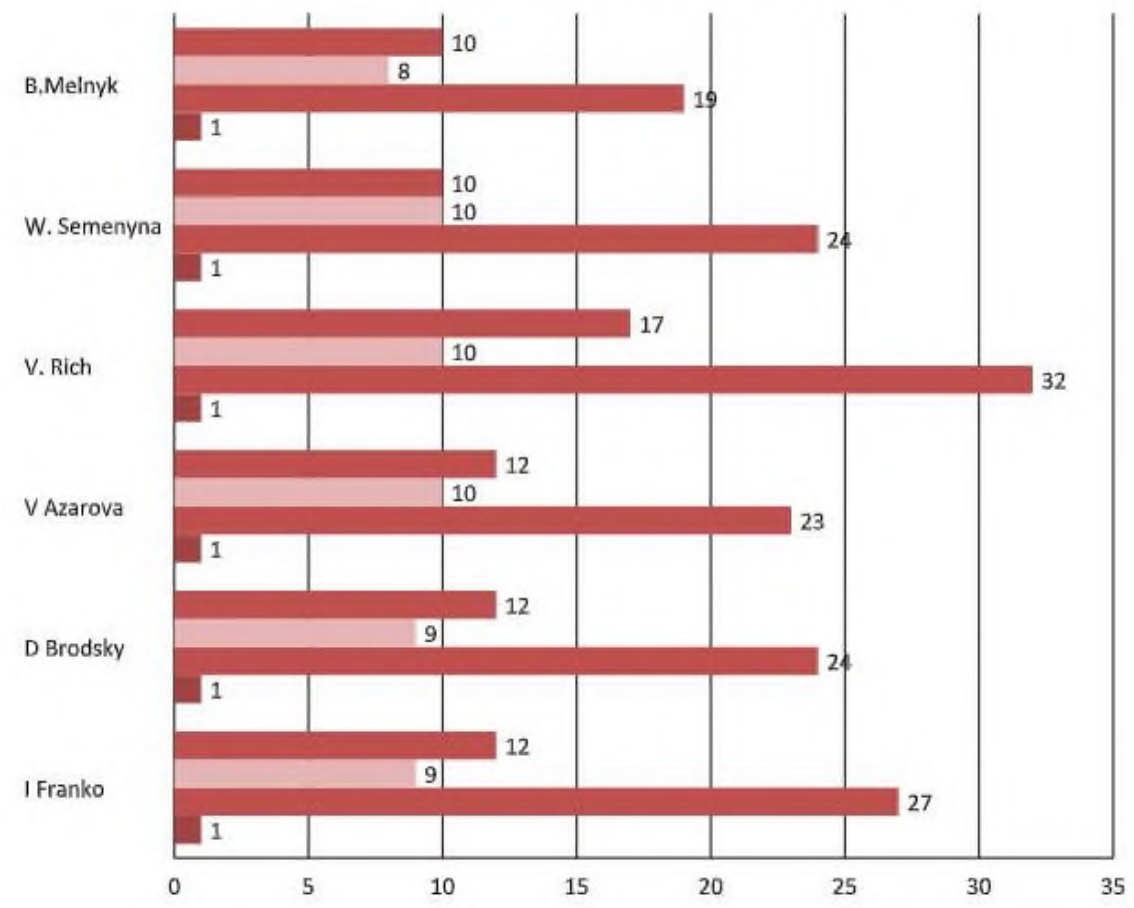

Fig. 1. The quantitative aspect of the comparative analysis of the biblicalisms of the poem "Moses".

\section{Discussion of research results}

The application of mathematical methods is a working tool for mathematical linguistics. Since the artistic space of the text is a kind of indicator of the presence of expressive functions of the same toponym, from use to use, the onym accumulates semantic characteristics and acquires new emotional connotations, both in translations of one text and in another artistic space. Poetic translation of toponymic units is most often accompanied by changes in the semantic load vector of the original text in the absence of an expressive equivalent in the target language.

\section{Conclusion}


The relevance of the comparative aspect, taking into account the problems of translations into Russian and English, the definition of the volume and the formation of the structure of the main functions of the studied biblicalisms in literary texts can serve as a basis for further research on this topic. The use of quantitative analysis allows for a more accurate and in-depth analysis of text units, to track the frequency and nature of their use in texts, to build the concept of analysis and clearly trace the prospect of further research on this scientific problem.

This paper has been supported by the RUDN University Strategic Academic Leadership Program.

\section{References}

1. N.V. Vasilyeva, Proper name in the world of text. Edition 2, rev. (M.: Book house "LIBROKOM", 2009)

2. V.M. Kalinkin, Poetics of onyms (Donetsk, 1999)

3. A.V. Superanskaya, General theory of proper names (M.: "Science", 1973)

4. I.Ya. Franco, Moses: Poema (Drogobich: "Kolo", 2005)

5. I. Franko, Moses translated by Vira Rich. Electronic Library of Ukrainian Literature.

6. I. Franko, Moses poem (Translated from the Ukrainian by Waldimir Semenyna. New York, 1938)

7. I. Franko, Selected Works (Translation from Ukrainian edited by M.F. Rylsky and B.A. Turganov. Moscow: State Publishing House of Fiction, 1945)

8. I. Franko, The poet of Western Ukraine Selected Poems Translated with a biographical ntroduction by Percival Cundy (Philosophical library, New York, 1948)

9. I. Franko, Selected works: Translated from Ukrainian (Introduced article, compiled note. M. Parkhomenko; Artist. V. Yakubich. - M .: Art. lit., 1981)

10. I. Franko, Moses, Basilian Press (trans. from Ukr. By B.Melnyk, Toronto, 2002)

11. O.I. Fonyakova, Proper name in literary text. Tutorial (Leningrad, 1990) 